\title{
Spinal artery syndrome masked by postoperative epidural analgesia
}

Stephan M. Linz MD, Christopher Charbonnet MD, Maged S. Mikhail MD, Nippon Vadehra MD, Vladimir Zelman MD, Ronald L. Katz MD, Duraiyah Thangathurai MD FRCA

Purpose: We report a case of a patient who developed a postoperative anterior spinal artery syndrome that was masked by the use of epidural analgesia. We wish to alert other anaesthetists that the use of epidural anaesthesia in this setting may mask the symptoms and delay the diagnosis of this rare complication.

Clinical features: The patient was a 22-yr-old obese man with metastatic testicular carcinoma who underwent a left-sided thoracoabdominal retroperitoneal tumour resection. A lumbar epidural catheter was placed preoperatively for pain management. Postoperatively, the patient developed bilateral lower extremity weakness, which was at first attributed to epidural administration of local anaesthetics. Despite discontinuation of the local anaesthetics, the symptoms persisted. Further work-up led to the diagnosis of anterior spinal artery syndrome. The patient was sent to a rehabilitation hospital and had a partial recovery.

Conclusion: Anterior spinal artery syndrome can occur following retroperitoneal surgery. It is important to recognize the potential for this complication when postoperative epidural analgesia is contemplated, especially following a left-sided surgical dissection. The use of epidural local anaesthetics immediately after surgery delays the diagnosis of a postoperative neurological deficit. Moreover, when the deficit is recognized the epidural itself may be falsely blamed for postoperative paraplegia. If epidural analgesia is used, opioids may be preferred over local anaesthetics in the immediate postoperative period to prevent masking of an anterior spinal artery syndrome.

Objectif : Rapporter un cas de syndrome de l'artère spinale antérieure masqué par une anesthésie épidurale dans le but de prévenir les anesthésistes que, dans ces conditions, l'anesthésie épidurale peut dissimuler les symptômes de cette complication exceptionnelle et en retarder le diagnostic.

Éléments cliniques : Un patient obèse âgé de 22 ans atteint d'un carcinome testiculaire métastatique a subi une résection thoracoabdominale de tumeur rétropéritonéale. Un cathéter lombaire épidural avait été inséré avant lintervention pour le traitement de la douleur. En postopératoire, le patient a présenté une faiblesse bilatérale des membres inférieurs qui fut d'abord attribuee à l'administration épidurale de l'anesthésique local. Malgré l'interruption de l'anesthésie régionale, les symptômes ont persisté. Un bilan ultérieur a conduit au diagnostic de syndrome de l'artère spinale antérieure. Une récupération partielle a suivi son hospitalisation dans un centre de réhabilitation.

Conclusion : Le syndrome de l'artère spinale antérieure peut survenir après une chirurgie rétropéritonéale. II est important de reconnaîre l'éventualité de cette complication si on considère administrer une anesthésie épidurale, surtout après une dissection du côté gauche du corps. L'administration épidurale d'un anesthésique local immédiatement après la chirurgie retarde le diagnostic d'un déficit neurologique postopératoire. En outre, même si on parvient à diagnostiquer un déficit, l'épidurale peut être blâmée à tort pour la paraplégie postopératoire. Si l'analgésie épidurale est choisie, il est préférable d'utiliser un morphinique plutôt qu'un anesthésique local à la période postopératoire immédiate pour éviter que le syndrome de l'artère spinale antérieure ne passe inaperçu dans l'immédiat.

From the Department of Anesthesiology, University of Southern California School of Medicine, Intensive Care Unit, Norris Cancer Hospital, 1441 Eastlake Avenue, Room 441, Los Angeles, CA, 90033 USA.

Address correspondence to: Duraiyah Thangathurai MD; Phone: 213-764-3441; Fax: 213-764-0084; E-mail: thangath@hsc.usc.edu Accepted for publication July 30, 1997. 


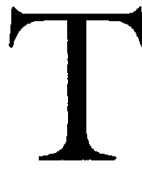

ESTICULAR cancer is the most common malignancy in men between the ages of 15 and 34 yr. $^{1}$ Lymphatic spread occurs along periaortic lymph nodes. Scardino and Skinner have shown that chemotherapy with bleomycin and cisplatinum followed by aggressive dissection of the retroperitoneum and periaortic lymphadenectomy is curative. $^{2}$ The surgery involves resection of the retropertioneal tissues and lymphatics from the pelvis to the level of the diaphragm. ${ }^{3,4}$ The thoracoabdominal incision, which is utilized to obtain adequate surgical exposure, results in severe postoperative pain that can be effectively managed with epidural local anaesthesia. We report a patient in whom a lumbar epidural catheter was placed preoperatively for a left-sided thoracoabdominal retroperitoneal resection and who developed anterior spinal artery syndrome in the postoperative period.

\section{Case report}

A 22-yr old, 170-kg man with a history of a mixed embryonal and seminomatous germ cell tumour was referred for a left thoracoabdominal retroperitoneal resection of a large supra-hilar retroperitoneal mass. He had previously undergone radical orchiectomy, followed by 11 courses of chemotherapy with bleomycin and cisplatinum. Preoperative tests including haemoglobin, serum creatinine and electrolytes, 12 lead ECG, and chest x-ray were normal.

Combined general and epidural anaesthesia was planned. An epidural catheter was placed in the L3-4 interspace. A $3 \mathrm{ml}$ test dose of lidocaine $1.5 \%$ with 5 $\mu \mathrm{g} \cdot \mathrm{ml}^{-1}$ epinephrine was negative for intravascular or intrathecal injection. General anaesthesia was induced with $500 \mathrm{mg}$ thiopentone followed by $140 \mathrm{mg}$ succinylcholine to facilitate tracheal intubation. An arterial line, central line and two additional large bore intravenous cannulas were placed. General anaesthesia was maintained with isoflurane $(0.5-1.5 \%)$ and intermittent doses of fentanyl $(750 \mu \mathrm{g}$ total). After an initial $10 \mathrm{ml}$ epidural bolus of lidocaine $2 \%$, additional doses of $5 \mathrm{ml}$ lidocaine $2 \%$ were given approximately every hour for a total of $50 \mathrm{ml}$. Vecuronium was used for muscle relaxation. The inspired oxygen concentration was kept between 20 and $30 \%$ because of the previous bleomycin therapy.

Only a slight hyperlordotic position was employed because of the patient's morbid obesity. The operative technique involved exposure of the large retroperitoneal mass through a left thoracoabdominal incision with resection of the seventh rib. Surgical exploration revealed a large retroperitoneal mass involving the left renal hilum, extending from the left iliac fossa to the left crux of the diaphragm. The tumour encased the mesenteric vessels, aorta, and inferior vena cava. It extended medially beyond the midline and laterally into the left flank. During the dissection, multiple intercostal arteries and aortic branches were ligated for haemostasis and to facilitate tumour removal. The entire mass was resected with a left en bloc nephrectomy.

A nitroglycerin infusion maintained the mean arterial blood pressure between $80-85 \mathrm{mmHg}$, to reduce surgical blood loss and provide an adequate surgical field. The patient's systolic arterial pressure never decreased below $100 \mathrm{mmHg}$. A mannitol infusion $(50 \mathrm{~g})$ was used for renal protection. The estimated blood loss was $7000 \mathrm{ml}$ during the procedure which lasted approximately $12 \mathrm{hr}$. Fluid replacement consisted of crystalloid $(7000 \mathrm{ml})$, albumin $5 \%(3000 \mathrm{ml})$, packed red blood cells (10 units), and fresh frozen plasma (3 units). Total urine output was $1100 \mathrm{ml}$. At the end of surgery, the patient was taken to the intensive care unit. The trachea was extubated after one hour. Postextubation arterial blood gas analysis showed $\mathrm{pH} 7.42$, $\mathrm{PCO}_{2} 37 \mathrm{mmHg}, \mathrm{PO}_{2} 99 \mathrm{mmHg}, \mathrm{HCO}_{3} 24 \mathrm{meq} \cdot \mathrm{l}^{-1}$, $\mathrm{SaO}_{2} 96 \%\left(\mathrm{FiO}_{2}=0.3\right)$. Postoperative pain was managed with $5 \mathrm{mg}$ epidural morphine at the end of the procedure and $5 \mathrm{ml}$ lidocaine $1 \%$ on arrival in the intensive care unit. Five $\mathrm{ml}$ bupivacaine $0.5 \%$ were given epidurally three hours and again nine hours later in the intensive care unit. He also received intercostal blocks with $3 \mathrm{ml}$ bupivacaine $0.5 \%$ above and below the resected rib on arrival and eight hours later to control pain at the chest tube site. Coagulation tests (prothrombin and partial thromboplastin times) and the platelet count were within normal limits shortly after admission to the intensive care unit.

The patient complained of bilateral lower extremity weakness on the first postoperative day, which was attributed to the epidural local anaesthesia. However, the weakness persisted despite discontinuing the local anaesthetics. On the second postoperative day, he was noted still to have motor weakness ( $\mathrm{Ll}$ to $\mathrm{Sl}$ ) with intact sensation and proprioception; rectal tone was also absent. The patient's obesity prevented CAT scan or MRI studies of the thoracolumbar spine to rule out an epidural haematoma secondary to the epidural catheter. An emergency myelogram was normal. After extensive neurological evaluation and consultation, a diagnosis of anterior spinal artery syndrome was made. The patient's symptoms persisted after several weeks of aggressive physical therapy, and he was transferred to a rehabilitation hospital. Eventually he regained some motor function of his left leg, and full bowel and bladder control, but his right leg remained paralysed without improvement. 


\section{Discussion}

We present a case of postoperative anterior spinal artery syndrome in a young patient who underwent left-sided thoracoabdominal retroperitoneal tumour resection. Use of lumbar epidural anaesthesia with local anaesthetics in the immediate postoperative period masked and delayed the diagnosis of paraplegia. An epidural haematoma was initially suspected and had to be excluded by myelography because the patient was too obese for the CT and MRI scanners. Although epidural anaesthesia delayed the diagnosis, the delay did not likely alter neurological outcome.

Our patient's neurological manifestations were most consistent with an anterior spinal artery syndrome which is a rare complication of this type of surgery. ${ }^{5} \mathrm{An}$ MRI scan of the spinal cord would have been helpful in confirming the diagnosis ${ }^{6}$ but was not possible in this case. Anterior spinal artery syndrome is characterized by flaccid paralysis of the lower extremities, usually with relative sparing of sensation and proprioception; ${ }^{7}$ loss of bowel and bladder function is also common. ${ }^{8}$ Its aetiology is thought to be ischaemia of the anterior spinal cord due to injury to the spinal artery of Adamkiewicz ${ }^{5,9}$ or following severe hypotension. ${ }^{8}$ Spinal cord injury during epidural needle placement was unlikely in this patient because the needle was introduced at the L3-4 vertebral level, well below the conus medullaris. Nerve root injury would have been expected to produce unilateral dermatomal or combined sensory and motor deficits without bowel or bladder dysfunction. A cauda equina syndrome resulting from unrecognized intrathecal injection of local anaesthetic ${ }^{10}$ was unlikely as the patient had intact perineal sensation and primarily a LlS1 motor deficit. The hyperlordotic position has been implicated in the aetiology of postoperative paraplegia, ${ }^{11}$ but most reported cases appear also to involve periods of considerable hypotension. ${ }^{12,13}$ Moreover, only mild hyperlordosis was used in our patient because of his morbid obesity. Our patient also did not experience any episodes of hypotension during surgery. Djurberg and Haddad reported a patient who developed postoperative anterior spinal artery syndrome following oesophagectomy in the lateral position. ${ }^{14}$ Although they did not describe the surgical technique, hypotension and a labile blood pressure appear to have played a major role.

Retroperitoneal dissection and periaortic lymphadenectomy for testicular tumours are usually carried out through a thoracoabdominal incision and usually involve ligation of the intercostal and other segmental collateral arteries arising from the aorta. ${ }^{15}$ The blood supply to the spinal cord consists of one anterior and two posterior spinal arteries which descend along the entire length of the spinal cord. ${ }^{8}$ These vessels arise from the vertebral arteries and receive collateral flow from the intercostal and lumbar branches of the descending aorta. In the lower thoracic and lumbar regions, the posterior arteries receive collateral flow from multiple intercostal and lumbar arteries, but the anterior spinal artery typically receives almost all of its collateral flow from a single vessel, the artery of Adamkiewicz. The variable origin and lengthy angular course of the artery of Adamkiewicz make it vulnerable to injury during extensive retroperitoneal dissections. The artery nearly always arises from a left intercostal artery or lumbar branch of the aorta anywhere between T6 and L3; 8,9 it arises between $\mathrm{T} 10$ and $\mathrm{T} 11$ in $75 \%$ of individuals. ${ }^{9}$ The only definitive method to confirm its origin is by preoperative angiography. ${ }^{16} \mathrm{~A}$ modification to the standard surgical for thoracoabdominal lymph node dissection has recently been described to preserve the collateral blood flow to the spinal cord. ${ }^{5}$

Postoperative anterior spinal artery syndrome most commonly occurs after operations involving the descending thoracic aorta, especially after prolonged cross-clamping of the aorta. ${ }^{17}$ However, the syndrome can also present following any retroperitoneal surgery when the artery of Adamkiewicz has a lumbar origin and its blood flow is compromised. Thus anterior spinal artery syndrome can also occur following abdominal aortic surgery, ${ }^{9,18}$ left-sided nephrectomies, as well as resections of pancreatic and other retroperitoneal tumour debulking procedures. ${ }^{5}$ Recognizing the potential for this complication following any left-sided retroperitoneal dissection is important to anaesthetists especially when epidural anaesthesia is considered. Although intraoperative monitoring of spinal evoked potentials has been reported to be helpful, ${ }^{19}$ this technique is not well established nor widely available. Epidural anaesthesia can delay diagnosis and be falsely blamed for postoperative paraplegia. If an epidural catheter is placed preoperatively, epidural opioids may be preferred to local anaesthetics to prevent masking early symptoms of lower extremity weakness. When local anaesthetics are used intraoperatively, they should be administered in dilute concentrations to prevent motor weakness and timed to allow adequate neurological assessment in immediate postoperative period.

\section{References}

1 Richie JP. Diagnosis and staging of testicular tumors. In: Skinner DG, Lieskovsky G (Eds.). Diagnosis and Management of Genitourinary Cancer. Philadelphia: W.B. Saunders, 1988: 498-507.

2 Scardino PT, Skinner DG. Germ-cell tumors of the testis: improved results in a prospective study using 
combined modality therapy and biochemical tumor markers. Surgery 1979; 86: 86-93.

3 Scardino PT. Thoracoabdominal retroperitoneal lymphadenectomy for testicular cancer. In: Crawford ED, Borden TA (Eds.). Genitourinary Cancer Surgery. Philadelphia: Lea \& Febiger, 1982: 271-89.

4 Fujioka T, Nomura K, Okamoto $T$, Aoki H, Obhori $T$, $K u$ bo $T$. Retroperitoneal lymph node dissection for testicular tumors using the thoracoabdominal approach. Int Surg 1993; 78: 154-8.

5 Leibovitch I, Nash PA, Little JS Jr, Foster RS, Donohue $J P$. Spinal cord ischemia after post-chemotherapy retroperitoneal lymph node dissection for nonseminomatous germ cell cancer. J Urol 1996; 155: 947-51.

6 Mawad ME, Rivera V, Crawford S, Ramirez A, Breitbach $W$. Spinal cord ischemia after resection of thoracoabdominal aortic aneurysms: MR findings in 24 patients. American Journal of Neuroradiology 1990; 11: 987-91.

7 Patten J. Neurological Differential Diagnosis. New York: Springer Verlag, 1980: 153.

8 Singh U, Silver JR, Welply NC. Hypotensive infarction of the spinal cord. Paraplegia 1994; 32: 314-22.

9 Szilagyi DE, Hageman JH, Smith RF, Elliott JP. Spinal cord damage in surgery of the abdominal aorta. Surgery 1978; 83: 38-56.

10 Cheng $A C K$. Intended epidural anesthesia as a possible cause of cauda equina syndrome. Anesth Analg 1994; 78: 157-9.

11 Amoiridis $G$, Wobrle JC, Langkafel M, Maiwurm D, Przuntek $H$. Spinal cord infarction after surgery in a patient in the hyperlordotic position. Anesthesiology 1996 84: 228-30.

12 Skouen JS, Wainapel SF, Willock MM. Paraplegia following epidural anesthesia. A case report and a literature review. Acta Neurol Scand 1985; 72: 437-43.

13 Urquhart-Hay D. Paraplegia following epidural analgesia. Anaesthesia 1969; 24: 461-70.

14 Djurberg $H$, Haddad $M$. Anterior spinal artery syndrome. Paraplegia following segmental ischaemic injury to the spinal cord after oesophagectomy. Anaesthesia 1995; 50: 345-8.

15 Lumsden $A B$, Colborn GL, Sreeram S, Skandalakis LJ. The surgical anatomy and technique of the thoracoabdominal incision. Surg Clin North Am 1993; 73: 633-44.

16 Savader SJ, Williams GM, Trerotola SO, et al. Preoperative spinal artery localization and its relationship to postoperative neurologic complications. Radiology 1993; 189: 165-71.

17 Gharagozloo $F$, Larson J, Dausmann MJ, Neville RF Jr, Gomes $M N$. Spinal cord protection during surgical procedures on the descending thoracic and thoracoabdominal aorta. Review of current techniques. Chest 1996; 109: 799-809.
18 Gloviczki $P$, Cross $S A$, Stanson $A W$, et al. Ischemic injury to the spinal cord or lumbosacral plexus after aorto-iliac reconstruction. Am J Surg 1991; 162: 131-6.

19 Grabitz K, Freye E, Stübmeier K, Sandmann, W. Spinal evoked potential in patients undergoing thoracoabdominal aortic reconstruction: a prognostic indicator of postoperative motor deficit. J Clin Monit 1993; 9: 186-90. 